\title{
STUDIES ON COLLISION-PROTECTIVE STRUCTURES
}

\section{IN NUCLEAR POWERED SHIPS}

\author{
Yoshio AKITA \\ The Ship Classification Society of Japan, Tokyo, Japan \\ Noritaka ANDO \\ The Ship Research Institute, Tokyo, Japan \\ Yuzuru FUJITA \\ The University of Tokyo, Tokyo, Japan \\ Katsuhide KITAMURA \\ Ishikawajima-Harima Heavy Industries Co., Ltd., Tokyo, Japan
}

The purpose of these studies is to obtain design data of collision-protective side structures installed in nuclear powered ships, which can be expected to absorb enough energy in a collision accident. Various test series and theoretical analyses were carried out by the Committee at Japan Shipbuilding Research Association during 1966-1969. These tests simulate the destruction behavior in which a wedge shaped stem penetrates the side structure of nuclear powered ship statically as well as dynamically. Side structure models having various types of structures, for instance, multicellar structures, transverse framed structures as well as longitudinal framed structures were tested.

In these models, tests on statical penetration by a rigid stem into models of various side structures were conducted and the conditions of the side structures required to have a large energy absorbing potential were examined. As the result, it was clarified that efficient structures are those which have transverse stiffening members in the deck portion so as to prevent transverse buckling of the decks.

In a study on the effect of the thickness of plates and other scantlings of side structures to the energy absorption in the case of penetration by rigid stem, statical penetration tests of a rigid stem into plate elements and box shaped structural models were conducted respectively, then the destruction mechanism and the absorbed energy were analyzed. Destruction modes of side structures were observed to be grouped into two types such as buckling type and shearing type, respectively, depending on types of side structures. Predictions of destruction mode of side structures and estimation of load, and absorbed energy against penetration depth were formulated. In order to examine the dynamical effects on destruction behavior, dynamical penetration tests of a rigid stem into box shaped structural models were conducted. The dynamical effects were shown to increase the absorbed energy by nearly 50\% and could be explained well by taking account of the rise of yield stress of steel due to increased strain rate.

In a study on influence of the strength of a stem of colliding ship to the destruction of side structures, penetration tests were conducted between the elastic stems of various strength and side structures. Relationships between strength ratio of stem to side structure and absorbed energies of side structures as well as stems were obtained. Using test results, semi-empirical formulas of the energy absorption were obtained.

In a study on the effect of stem angle to the energy absorption, penetration tests of rigid stems with stem angle of $20^{\circ}$ through $80^{\circ}$ were conducted and its effect were revealed to be small.

In a study on the effect of colliding angle between colliding ship and collided ship, inclined penetration tests in colliding angles of $60^{\circ}$ and $70^{\circ}$ were conducted and consequently the absorbed energy of side structures was shown to be almost the same as that in normal collision.

In a study on virtual mass at collision, the motions of two ships were hydrodynamically treated and a relationship between virtual mass and elapsed time of collision was analyzed by the so-called strip method. On the other hand, collision tests of model ships in water were conducted and test results were compared with analytical ones so as to obtain the virtual mass.

\footnotetext{
* Published in Nuclear Engineering and Design 19 (1972) 365-401.
} 


\section{DISCUSSION}

Q

G. WOISIN, Germany

At first I want to congratulate Mr. Akita to his excellent and comprehensive paper on the subject of collision protection of reactor ships. I believe, In Japan has been done the greatest deal of research on this problem in the world. In Japan have been done the most structural model tests until now.

I would like to put three questions to Mr. Akita :

1. How did you do in Japan with the joints of materials in the models: did you always weld them like it is done in real ships today? Or did you have sometimes also some soft soldered joints in your models? The purpose could be to avoid too big dislocations arising in fabrication?

2. Could you please give us some informations about tests, which in Japan have been carried out with real structure models of a bulbous bow on one hand and a side model of the "MUTSU"collision barrier on the other. I believe it was the coauthor N. Ando who - in a series of reports about the "MUTSU", published in the journal "Nuclear Engineering and Design" 10 (1969) - mentioned a collision test of this kind made in Japan. Can you please give some details on :

- the special purpose of these tests,

- the number of tests of this kind,

- whether the test was statically or dynamically carried out,

- size of model scale and the main results.

3. What do you think about the possible existence of a scale effect by embrittlement. I mean especially the danger of embrittlement in reality in case of a strong collision protection barrier. Even if there is no embrittlement in model tests this could happen, I believe, because of the existence of a difference of transitional temperatures between model and full scale, and because of its unknown size. I should like to know your opinion about this aspect.

\section{A Y. AKITA, Japan}

1. The joints of the structural model were arc welded continuously. The thickness of plates used in the model were $2.3 \mathrm{~mm}$ and $3.2 \mathrm{~mm}$. Distortions or dislocations were not observed. 2. The $1 / 10$ scale model tests of collision between "MUTSU" and a supermammoth tanker of 150,000 DWT, tanker "TOKYO MARU", were carried out by the Japan Nuclear Ship Development Agency with cooperations of Prof. Ando and IHI Company. The purpose of the experiment is to make clear the fracture mechanism of collision between nuclear powered ship and bulbous bow which has soft structure and is relatively larger in size. The test was made statically. The results showed that the bulbous bow collapsed in very early stage and the energy absorption for this case can be calculated as bulbless stem.

3. I agree with your opinion on the existence of scale effect. However, I believe if we know the $\mathrm{K}_{\mathrm{I}}$ values of the steel plates of the model ship and actual ship, we can estimate the mode of fracture (brittle or ductile) from model tests carried out at several temperatures. 
$Q$ K. A. RECKLING, Germany

Which of the both ways of protecting a nuclear powered ship is the best according to your experience and test. The protection by strengthening the outer hull or by strengthening the decks? Or should one combine the two possibilities?

\section{A Y. AKITA, Japan}

It is difficult to say the general conclusion for the question of Prof. Reckling. However, the following may be said. If we increase the thickness of the deck plate, the mode of fracture tends to the "crack type", and if we increase the thickness of the side shell, it tends to the "deformation type".

The energy absorption changes proportionally to the square of the penetration in the case of crack type and linearly proportional in the deformation type. Therefore, the curve of absorbed energy against penetration is shown in parabola and straight line starting from the origin, respectively. These curves generally cross each other at a certain point. If the penetration allowed in the design is larger than the penetration corresponding to the cross point, then the absorbed energy in crack type is larger than that of deformation type, and vice versa.

\section{RISSE, Germany}

In one of your last slides you showed the comparison between the nuclear ships "SAVANNAH" and "MUTSU" on the one and some other ships on the other side. Could you please give a feeling, how much such a ship penetrates into a nuclear ship ? Did you make such calculations? How much does this mean in meters of penetration?

\section{A Y. AKITA, Japan}

The last slide shows that if the collision between MUTSU and ice breaker (FUJI) of high speed and collision between SAVANNAH and the same ice breaker are compared, the penetrations reach to the boundaries of the reactor rooms respectively for both cases $(\beta=$ 1 for both cases).

However, for the collision between T-2 tanker the penetration in the case of MUTSU is approximately half $(=3.8 / 7.1)$ of that in the case of SAVANNAH. 